ARTIGO

Recebido em: $12 / 11 / 2017$

Aceito em: 04/04/2018

\title{
Exclusão e inclusão digitais em bibliotecas públicas municipais da Região Metropolitana de Belo Horizonte: análise do serviço de acesso à internet disponibilizado pelas instituições para o exercício da cidadania
}

Digital exclusion and inclusion in municipal public libraries in the Região Metropolitana de Belo Horizonte: analysis of Internet access service offered by institutions for the exercise of citizenship

\begin{tabular}{c}
\hline Luciana Gonçalves Silva SOUZA (lucianags9@gmail.com)* \\
Lígia Maria Moreira DUMONT (dumont@eci.ufmg.br)** \\
* Mestre em Ciência da Informação pela Escola de Ciência da Informação da Universidade Federal de \\
Minas Gerais (UFMG). Bibliotecária-documentalista na UFMG. \\
** Professora Titular da Escola de Ciência da Informação (ECI) da \\
Universidade Federal de Minas Gerais (UFMG).
\end{tabular}

\section{Resumo}

Aborda a ampliação do exercício da cidadania para os meios digitais e os empecilhos ocasionados por essa modalidade de acesso às informações devido aos altos índices de exclusão digital da população brasileira. A internet se caracteriza como um importante meio de ampliação de acesso às informações, mas exige habilidades para uma navegação que possa suprir as necessidades informacionais do usuário. Nesse sentido, iniciativas de promoção da inclusão digital são necessárias. A biblioteca pública é a instituição que possui condições de proporcionar essa inclusão, capacitando usuários para a busca e uso de informações. A pesquisa buscou identificar instituições que fornecem o acesso à internet para a comunidade, compreendendo a constituição das iniciativas amparadas por políticas públicas de inclusão digital e analisando o serviço oferecido à comunidade.

Palavras-chave: Bibliotecas públicas. Cidadania digital. Inclusão digital. Serviço de acesso à internet.

\begin{abstract}
It addresses the expansion of the exercise of citizenship for digital media and the obstacles caused by this modality of access to information due to the high digital exclusion rates of the Brazilian population. The Internet is characterized as an important means of increasing access to information, but requires skills for a navigation that can meet the informational needs of the user. In this sense, initiatives to promote digital inclusion are necessary. The public library is institution that is able to provide this inclusion, enabling users to search and use information. The research sought to identify institutions that provide Internet access to the community, including the constitution of supported initiatives by public policies of digital inclusion and analyzing the service offered to the community.

Keywords: Public libraries. Digital citizenship. Digital inclusion. Internet access service.
\end{abstract}

v. 23, n. $52,2018$. p. $48-60$

ISSN 1518-2924
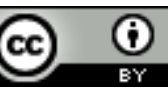


\section{INTRODUÇÃO}

As Tecnologias de Informação e Comunicação (TIC) transformaram a relação da sociedade com a informação, alterando as possibilidades de seu acesso, uso e disseminação. Com isso, há uma nova configuração social, que possui como instrumento de valor a informação e o conhecimento, denominada por Daniel Bell (1973) como Sociedade da Informação. A internet é recurso essencial nessa transformação, ampliando o alcance geográfico e social das redes e proporcionando produção, troca e apropriação de conhecimentos (CASTELLS, 2003; MARTELETO, 2010).

Com a expansão da rede, alguns serviços relacionados à prática cidadã passam a ser oferecidos apenas pela internet ou têm seu acesso facilitado e incentivado nesse meio. São serviços que integram a cidadania digital, iniciativas que objetivam facilitar o acesso aos mesmos, mas que, diante de uma realidade de exclusão digital de grande parcela da população brasileira, geram impedimentos pela distinção do meio de execução do serviço. Neste sentido, a pesquisa Retratos da Leitura no Brasil, realizada em 2016, relata que, mesmo diante da expansão do acesso à internet em meios como smartfones e tablets, equipamentos mais acessíveis economicamente que computadores pessoais, apenas $63 \%$ dos respondentes se declararam usuários da internet, enquanto $33 \%$ afirmaram que nunca acessaram a rede (INSTITUTO PRÓ-LIVRO, 2016).

Dessa forma, apesar do salto tecnológico verificado nos últimos anos, ainda existe um alto número de indivíduos que não têm acesso facilitado à internet. Compreende-se, ainda, que as pesquisas que quantificam esse acesso não consideram a qualidade do uso da rede. Essas condições refletem aspectos relacionados à exclusão digital.

Nesse sentido, governos, empresas e organizações do terceiro setor identificaram a necessidade de desenvolver ações relacionadas à capacitação dos indivíduos para o acesso e o uso das TIC, tendo em vista a inclusão digital. Telecentros e espaços públicos como bibliotecas são locais que a população recorre para ter o acesso. As ações desenvolvidas pelas bibliotecas públicas, instituições mantidas pelo poder público, serão possíveis com a inclusão de políticas para a promoção da cidadania e da constituição de habilidades para busca e uso de informações digitais.

A Região Metropolitana de Belo Horizonte conta com um conjunto heterogêneo de municípios em relação à densidade populacional e às condições econômicas e sociais. A pesquisa analisou o serviço de acesso à internet oferecido por bibliotecas públicas municipais da região, considerando as instituições de municípios limítrofes à capital, Belo Horizonte, que forneciam computadores à comunidade atendida.

\section{REFERENCIAL TEÓRICO}

Para a fundamentação, apresentam-se os conceitos relacionados à cidadania digital, à exclusão e inclusão digitais e às bibliotecas públicas, compreendendo os serviços que desenvolvem, relacionadas à democratização do acesso à internet.

\subsection{Cidadania digital}

0 exercício pleno da cidadania deve combinar liberdade, participação e igualdade para todos, integrando os direitos civis, políticos e sociais, conforme Marshall $(1967$, p. 76). $\mathrm{O}$ autor aprofundou os estudos sobre a cidadania traçando sua argumentação sobre a prática cidadã a partir da igualdade social. Explica que "A cidadania é um status concedido àqueles que são membros integrais de uma comunidade. Todos aqueles que possuem o status são iguais com respeito aos direitos e obrigações pertinentes ao status".

Benevides (1994, p. 7) esclarece que, na teoria constitucional moderna, "[...] cidadão é o indivíduo que tem um vínculo jurídico com o Estado. É o portador de direitos e deveres fixados por uma determinada estrutura legal (Constituição, leis) que lhe confere, ainda, a nacionalidade". Nesse sentido, segundo o autor, o que se verifica são graus de direitos que se 
caracterizam mais como concessões, deixando de ser prestações a cidadãos legítimos, em igualdade de condições, para serem atribuídos a alguns. Essa seria a cidadania passiva, que exclui, característica de nações com elevado grau de desigualdade social, como o Brasil. Acrescenta: "A cidadania permaneceu parcial, desequilibrada, excludente. Direitos ainda entendidos como privilégios - só para alguns, e sob determinadas condições" (BENEVIDES, 1994, p. 7).

Assim, a cidadania digital é compreendida como a aplicação dos direitos sociais no ambiente eletrônico. Carvalho e Américo (2014, p. 77) explicam que o conceito está "intimamente relacionado à ampliação dos direitos já conquistados nos campos social, político, econômico e cultural também para as redes digitais, principalmente para aquelas que utilizam as tecnologias da informação e comunicação."

Essa relação entre a democracia e a tecnologia é vista por Sebastião, Pacheco e Santos (2012) como uma estrutura de poder depositado na população, que decide e o exerce, por meio da representação e que utiliza para simplificar, aprimorar e melhor acompanhar esse exercício representativo as tecnologias de informação e comunicação. A cidadania digital tem como propósito ampliar a participação popular nas decisões políticas e aproximar os representados de seus representantes.

Santos e Cardoso (2008) ressaltam o papel do Estado no sentido de prover o desenvolvimento tecnológico, sem propor empecilhos ao desenvolvimento das tecnologias de informação e comunicação pelos meios sociais, mas cuidando para que o avanço se dê com o objetivo de garantir maior acesso dos cidadãos, aproximando-os do Estado a partir das ferramentas digitais.

\subsection{Exclusão e inclusão digitais}

Diante da integração da tecnologia na democratização do acesso à informação, Lemos e Costa (2005, p. 2) discutem a questão afirmando que "estar inserido digitalmente passa a ser considerado um direito dos cidadãos e uma condição fundamental para a sua existência no mundo da informação e da comunicação globais".

A privação das tecnologias de informação e comunicação é identificada como exclusão digital. Sorj (2003) explicita que essa forma de exclusão está ligada não apenas à ausência do acesso à internet e seu uso, mas compreende a privação do acesso a outras tecnologias de informação. A exclusão digital é normalmente acompanhada de outras formas de exclusão, a saber:

A exclusão digital possui forte correlação com as outras formas de desigualdade social, e, em geral, as taxas mais altas de exclusão digital encontram-se nos setores de menor renda. A desigualdade social no campo das comunicações, na sociedade moderna de consumo de massas, não se expressa somente no acesso ao bem material - rádio, telefone, televisão, Internet -, mas também na capacidade do usuário de retirar, a partir de sua capacitação intelectual e profissional, o máximo proveito das potencialidades oferecidas por cada instrumento de comunicação e informação (SORJ, 2003, p. 59).

Assim, Silveira (2008, p. 43) aponta que "A ideia de exclusão foi introduzida na Sociedade da Informação para denunciar os processos que impedem a maioria da população de acessar a comunicação mediada por computador, ou seja, de utilizar as redes informacionais". É, segundo o autor, uma expressão já utilizada no contexto social para definir o posicionamento dos segmentos sociais diante dos direitos coletivos, utilizado nas Ciências Sociais, principalmente em formulação de políticas públicas. Dessa forma, a 
exclusão, quando relacionada ao contexto das novas mídias, caracteriza a privação do acesso e uso das redes informacionais digitais.

Lemos e Costa (2007) consideram o ato de incluir complexo e necessário à ampliação dos capitais técnico, cultural, social e intelectual ${ }^{1}$. Compreendem que o processo de inclusão digital deve atingir a dimensão econômica, quando se garante condições financeiras para acesso às tecnologias digitais, a dimensão cognitiva, perspectiva crítica e apropriação informacional a partir do uso independente das tecnologias, e a dimensão técnica, habilidade de operar programas e acessar a internet. Afirmam:

Incluir não deve ser apenas uma simples ação de formação técnica dos aplicativos, como acontece na maioria dos projetos, mas um trabalho de desenvolvimento das habilidades cognitivas, transformando informação em conhecimento, transformando utilização em apropriação. A reflexão crítica da sociedade deverá gerar práticas criativas de recusa de todas as formas de exclusão social. A apropriação dos meios deve ocorrer de forma ativa (LEMOS; COSTA, 2007, p. 42-43).

Nessa definição, os autores identificam a proximidade existente entre a inclusão digital e políticas públicas, que se concretiza em projetos muitas vezes voltados ao desenvolvimento de habilidades técnicas, que não possibilitam a construção de reflexões críticas para o uso das tecnologias no desenvolvimento de atividades que satisfaçam necessidades informacionais. Nesta perspectiva, ressaltam a responsabilidade do Estado de prover condições para a prática cidadã, considerando que o acesso à informação está compreendido também no domínio das TIC. As políticas públicas devem indicar o caminho para a transformação social dos indivíduos.

\subsection{A biblioteca pública e os serviços relacionados à democratização da internet}

A biblioteca pública é caracterizada pela Fundação Biblioteca Nacional como o elo que une uma necessidade de informação de um usuário ao recurso informacional que lá está organizado e disponível. Dessa forma, a biblioteca precisa estar preparada para receber o usuário, "deve constituir-se em um ambiente realmente público, de convivência agradável, onde as pessoas possam se encontrar para conversar, trocar idéias, discutir problemas, autoinstruir-se e participar de atividades culturais e de lazer". (FUNDAÇÃO BIBLIOTECA NACIONAL, 2000, p. 17).

Tendo em vista a necessidade de constante atualização da coleção para suprir as necessidades informacionais de seus usuários, os materiais digitais e os recursos disponíveis em meio eletrônico precisam ser levados em consideração na constituição do acervo das bibliotecas públicas, como apregoa o Manifesto sobre Bibliotecas Públicas:

Todos os grupos etários devem encontrar documentos adequados às suas necessidades. As colecções e serviços devem incluir todos os tipos de suporte e tecnologias modernas apropriados assim como fundos tradicionais. É essencial que sejam de elevada qualidade e adequadas às necessidades e condições locais (INTERNATIONAL FEDERATION OF LIBRARY ASSOCIATIONS AND INSTITUTIONS, 1994).

1 Definidos, de acordo com Lemos (2004), como: “O capital cultural é a memória de uma sociedade, o social, a potência política e identitária, o intelectual, a competência individual, e o técnico a potência da ação e da comunicação" (LEMOS; COSTA, 2007, p. 42). 
A partir da necessidade de acompanhamento das tecnologias pelas bibliotecas públicas é que se estimula a ampliação das possibilidades de acesso à informação em formatos além do impresso, principalmente por meio do oferecimento de condições para o acesso e uso de conteúdo eletrônico via internet. Tal necessidade parte da constatação de que, neste contexto, com o advento da internet e virtualização dos acervos, questiona-se o papel da biblioteca como apenas depositária de conhecimentos (SILVA, 2004).

Assim, sendo essas instituições agentes de condução de transformações sociais, por possibilitar o acesso universal à informação, devem entender que sofrem influências constantes das tecnologias e precisam estar abertas ao processo de mudança, assim como a sociedade se vê em constante mutação. Cabe à biblioteca visualizar as demandas sociais que estão presentes em sua comunidade de ação e adaptar seus produtos e serviços para o adequado atendimento ao usuário. 0 bibliotecário, profissional responsável pela aquisição, tratamento, organização e transmissão de informações, precisa participar ativamente deste cenário de inovações, o que torna a sua atualização constante às novas tecnologias requisito essencial para o desempenho de seu fazer. No contexto tecnológico, as necessidades informacionais se alteram rapidamente, e o profissional deve se manter como orientador no processo, como explicita Santos (2002, p. 103).

Cuevas Cerveró e Vellosillo González (2011) evidenciam a função das bibliotecas como base de ações de inclusão social por meio do acesso às tecnologias. Afirmam:

Na atualidade, a biblioteca é uma instituição que permite livre acesso à informação. Pode se tornar uma protagonista no processo de inclusão digital e aprendizagem ao longo da vida e deve desempenhar um papel fundamental para compensar as desigualdades no acesso à tecnologia (CUEVAS CERVERÓ VELLOSILLO GONZÁLEZ, 2011, p. 57).

Nesse sentido, são identificados entre os serviços que podem ser desenvolvidos no contexto digital pelas bibliotecas públicas os serviços de informação à comunidade e o desenvolvimento de competências em informação, descritos a seguir.

\subsubsection{Serviços de informação à comunidade}

Suaiden (1995) explica que os serviços de informação à comunidade são uma forma de transformar a tradicional função informativa da biblioteca, inserindo algo mais vivo e que se adeque às necessidades diárias da comunidade, auxiliando a camada mais desfavorecida da população com informações úteis ao seu cotidiano. Para o autor, o conceito mais adequado para o serviço foi o elaborado pela Library Association Working Party of Community Information:

O serviço de informação à comunidade serve para resolver problemas, tanto de pessoas como de grupos, centrados nos temas mais importantes e enfrentados diariamente em relação à moradia, ao trabalho, aos direitos e que possam participar em sua solução, tanto os indivíduos como os grupos do contexto social, político e econômico, atribuindo-se então grande importância a que esta informação esteja adaptada às necessidades e possibilidades dos usuários. (THE LIBRARY ASSOCIATION, 1980 apud SUAIDEN, 1995, p. 69-70).

No contexto digital, com a disponibilização de computadores para acesso à internet nas bibliotecas públicas, vê-se uma importante fonte de acesso aos serviços de informação à 
comunidade. Podem ser reunidos, nas máquinas disponíveis, serviços que auxiliem o usuário no desenvolvimento de atividades como busca de empregos, preenchimento de currículos, acesso aos serviços do município e Estado, como a emissão de taxas como IPTU, IPVA, seguros, preenchimento de formulários para emissão de documentos, participação em serviços ao cidadão, como orçamento participativo, votações e petições online, abaixo assinados eletrônicos, entre outros. A Fundação Biblioteca Nacional explicita a necessidade da disponibilização de computadores para implantação do serviço da seguinte forma:

\begin{abstract}
A implantação do Serviço de Acesso Público à Internet, como um dos segmentos do SIC [Serviço de Informação à Comunidade], amplia o seu potencial de recuperação da informação, bem como cria a oportunidade para que os usuários da biblioteca se familiarizem com as novas tecnologias da informação e da comunicação. (FUNDAÇÃO BIBLIOTECA NACIONAL, 2000, p. 99).
\end{abstract}

Assim, a utilização de computadores como suporte à execução do serviço de informação à comunidade possibilitará à biblioteca integrar atividades que contribuem para o desenvolvimento da cidadania pelos membros da comunidade atendida, demonstrando diversas possibilidades de uso da internet e extensão das atividades oferecidas pela instituição.

\title{
2.3.2 Competência em informação no contexto digital
}

De acordo com Bundy (2001), competência em informação consiste em um conjunto de habilidades que possibilitam o reconhecimento de uma necessidade de informação e a capacidade de identificar, localizar, avaliar e efetivamente utilizar as informações necessárias.

A Declaração de Alexandria, publicada pela International Federation of Library Associations and Institutions (IFLA), defende a expansão da competência em informação a todos os tipos de bibliotecas do mundo. 0 documento "declara que a competência informacional e o aprendizado ao longo da vida são os faróis da Sociedade da Informação, iluminando os caminhos para o desenvolvimento, a prosperidade e a liberdade" e explica que a competência em informação, no contexto das tecnologias "vai além das tecnologias atuais para abranger o aprendizado, o pensamento crítico e as habilidades interpretativas cruzando as fronteiras profissionais, além de capacitar indivíduos e comunidades" (INTERNATIONAL FEDERATION OF LIBRARY ASSOCIATIONS AND INSTITUTIONS, 2005, p. 1).

Aplicada no contexto digital, a competência em informação atinge uma dimensão de cuidado na identificação dos conteúdos disponíveis na rede. Feres e Belluzzo (2009) esclarecem que a busca de informações no ambiente da internet é mais complexa e exige maior desenvolvimento de competências para lidar no ambiente. Afirmam:

Em uma sociedade em rede, considerando-se que a pesquisa virtual, apoiada na Internet, com seus milhões de sites de busca, ao mesmo tempo em que permite encontrar informações sobre todas as áreas do conhecimento em grande quantidade, criam-se novos problemas e uma grande complexidade para saber buscar e saber selecionar essas informações (FERES; BELLUZZO, 2009, p. 80).

Dessa maneira, a IFLA (2006) orienta as bibliotecas para a realização de treinamentos sobre acesso à informação na internet e técnicas avançadas de busca: 
Além dos muitos recursos valiosos disponíveis na Internet, podem ser encontrados alguns incorretos, enganosos e talvez ofensivos. Os bibliotecários devem fornecer aos usuários a informação e os recursos para que aprendam a usar eficiente e eficazmente a Internet. Eles devem proativamente promover e facilitar o acesso responsável à informação de qualidade em rede para todos os seus usuários, incluindo crianças e adolescentes (INTERNATIONAL FEDERATION OF LIBRARY ASSOCIATIONS AND INSTITUTIONS, 2006, p. 28, grifo do autor).

Assim, a biblioteca pública pode assumir esta função de divulgadora de informações também em formato digital, contribuindo para a redução do analfabetismo digital e informacional. Diante do exposto, foi desenvolvida a pesquisa, que visou identificar ações voltadas à inclusão de indivíduos na Sociedade da Informação, proporcionando o exercício da cidadania em ambientes digitais e o desenvolvimento das competências para busca e uso das informações.

\section{MATERIAL E MÉTODOS ${ }^{2}$}

Para analisar iniciativas de acesso à internet disponibilizadas por bibliotecas públicas municipais da Região Metropolitana de Belo Horizonte, utilizou-se como abordagem o método qualitativo, tendo em vista a subjetividade do objeto estudado e sua integração com diferentes atores. A pesquisa se desenvolveu a partir de três procedimentos: questionário, pesquisa documental e entrevista semiestruturada.

O questionário foi aplicado por e-mail e ligações telefônicas para identificar, entre as bibliotecas públicas municipais da Região Metropolitana de Belo Horizonte, aquelas que fornecem computadores com acesso à internet para uso da comunidade.

A pesquisa documental foi realizada em documentos públicos oficiais, tendo como fonte de consulta primária o Diário Oficial da República Federativa da União, páginas eletrônicas dos governos, bem como bibliotecas e repositórios digitais das instituições governamentais e estudos acadêmicos que apontavam legislações relacionadas às políticas públicas de inclusão digital. A partir dessas fontes foram identificadas as ações governamentais de inclusão digital e os instrumentos jurídicos que regiam a criação e aplicação das políticas. A investigação foi realizada com o objetivo de verificar, perante as políticas públicas de inclusão digital desenvolvidas nos âmbitos federal, estadual (Minas Gerais) e municipal (cidades da Região Metropolitana de Belo Horizonte: Belo Horizonte, Contagem, Ibirité, Ribeirão das Neves, Santa Luzia, Sabará, Vespasiano), aquelas que poderiam ser incorporadas pelas bibliotecas, possibilitando uma integração com a realidade vivenciada pelas bibliotecas públicas municipais da Região Metropolitana de Belo Horizonte.

Por fim, a entrevista semiestruturada com os gestores das bibliotecas municipais, grupo formado por servidores efetivos e contratados das instituições, objetivou compreender a constituição dos espaços de acesso à internet disponíveis nas bibliotecas, verificar se as políticas públicas desenvolvidas pelos governos têm, de fato, atingido as bibliotecas públicas municipais que oferecem o serviço e averiguar se as instituições desenvolvem aspectos relacionados à inclusão digital da comunidade atendida.

\section{RESULTADOS E DISCUSSÃo}

2 Pesquisa registrada pelo Comitê de Ética de Pesquisa da Universidade Federal de Minas Gerais, CAAE 71470917.2.0000.5149. 
A aplicação do questionário, primeira etapa da pesquisa, foi realizada com os 34 municípios que compõem a Região Metropolitana de Belo Horizonte. Foram recebidas 29 respostas, totalizando $85 \%$ de retorno. Perguntados sobre a presença de computadores com acesso à internet para uso da população atendida, 11 instituições afirmaram disponibilizar o serviço, conforme Quadro 1.

Quadro 1: Bibliotecas públicas da Região Metropolitana de Belo Horizonte e o acesso a computadores com internet

\begin{tabular}{ll}
\hline Município & $\begin{array}{l}\text { Acesso à internet para } \\
\text { uso da comunidade }\end{array}$ \\
\hline Belo Horizonte & Sim \\
Betim & Não \\
Brumadinho & Não \\
Caeté & Não \\
Confins & Não \\
Contagem & Sim \\
Florestal & Não \\
Ibirité & Sim \\
Igarapé & Sim \\
Itaguara & Sim \\
Jaboticatubas & Sim \\
Juatuba & Não \\
Lagoa Santa & Não \\
Mário Campos & Não \\
Mateus Leme & Não \\
Matozinhos & Não \\
Nova Lima & Não \\
Nova União & Não \\
Pedro Leopoldo & Não \\
Raposos & Sim \\
Ribeirão das Neves & Sim \\
Rio Acima & Não \\
Rio Manso & Não \\
Sabará & Sim \\
Santa Luzia & Sim \\
São Joaquim de Bicas & Não \\
São José da Lapa & Não \\
Sarzedo & \\
Vespasiano & Não \\
\hline &
\end{tabular}

Fonte: dados da pesquisa

Destas, foram identificadas sete instituições para participar da entrevista semiestruturada, utilizando o critério não probabilístico de proximidade, utilizando como referência a cidade de Belo Horizonte.

A pesquisa documental identificou políticas públicas de inclusão digital implementadas pelos governos federais, estaduais e municipais, verificando a construção de propostas que se adequam às bibliotecas, possibilitando a realização de práticas relacionadas à democratização do acesso às tecnologias de informação e comunicação nas instituições. Dadas como objeto de estudo da presente pesquisa, as bibliotecas públicas municipais são, como o nome aponta, instituições mantidas pelos municípios, cumprindo a 
função constitucional do Estado brasileiro de garantia de acesso à informação e à leitura (MACHADO; CALIL JUNIOR; AQUILES, 2014). As ações desenvolvidas nestas entidades são, em grande parte, impulsionadas por políticas públicas. Foram identificadas 27 ações dos governos, sendo 19 políticas públicas do âmbito federal, quatro políticas do Estado de Minas Gerais e quatro desenvolvidas no âmbito municipal, idealizadas apenas pela cidade de Belo Horizonte.

Para verificar a relação das políticas públicas de inclusão digital com a biblioteca, optou-se por identificar os programas, projetos e ações encontrados a partir de três condições: as políticas que mencionam a biblioteca em seus instrumentos normativos e textos orientadores, aquelas que não mencionam explicitamente a biblioteca, mas podem ser apropriadas pela instituição e, por último, políticas que não se destinam à biblioteca, alcançando outras instituições ou pessoas físicas.

Entre as 27 políticas públicas de inclusão digital encontradas pela pesquisa documental realizada, considerando as esferas federal, estadual e municipal, cinco citam a biblioteca em seus textos normativos, o que corresponde a $18 \%, 11$ podem ser apropriadas pela biblioteca, o que equivale a $41 \%$, e 11 não se aplicam ao contexto da instituição, constituindo $41 \%$.

A menção às bibliotecas nas políticas públicas de inclusão digital está ligada ao reconhecimento de seu papel como agente de inclusão digital, na maioria dos textos. Foram citadas no Projeto Casa Brasil, Projeto Computadores para Inclusão, Programa Mais Cultura e Programa BH Digital, constituindo três políticas públicas da instância federal e uma política do Município de Belo Horizonte. Com exceção do Projeto Casa Brasil, que apresentava um ambiente composto por vários espaços que visavam à transformação social da comunidade, entre eles o telecentro e a biblioteca, as demais políticas identificavam a biblioteca como um organismo democratizador apto a desenvolver a inclusão digital na comunidade, citando a instituição como possível recebedora de computadores e kits telecentros para acesso à internet.

Entre as 11 políticas públicas de inclusão digital que poderiam ser apropriadas pelas bibliotecas, quatro estão relacionadas à disponibilização de conexão banda larga a espaços públicos: Programa Governo Eletrônico - Serviço de Atendimento ao Cidadão (GESAC), Programa Nacional de Banda Larga (PNBL), Programa Cidades Digitais - Minha Cidade Inteligente e Hotspots. Duas compreendem a biblioteca como um espaço de apoio às atividades realizadas no telecentro: Programa Telecentro da Pesca Maré e Programa Universidade Aberta e Integrada de Minas Gerais - UAITEC. Três estão voltadas à doação e instalação de telecentros, indicando espaços para recebimento, que poderiam ser as bibliotecas: Programa Telecentros de Informação e Negócios (TIN), Programa Nacional de Apoio à Inclusão Digital nas Comunidades - Telecentros.BR e Programa Cidadão.NET. Uma se relaciona à instrução e apoio financeiro a monitores para desenvolvimento de cursos e atividades nos telecentros, que podem estar localizados nas bibliotecas, que é o Programa Nacional de Formação de Agentes de Inclusão Digital (Pnaid) e uma política pública busca angariar recursos financeiros para manutenção de telecentros, que podem estar dispostos em biblioteca, o Programa Adote um Telecentro.

Os demais programas, projetos e ações dos governos federal, estadual e municipal não se enquadram nas bibliotecas, seja por possuírem destinatários específicos, como é o caso dos Programas Nacional de Formação Continuada em Tecnologia Educacional (ProInfo Integrado), Programa Banda Larga nas Escolas, Projeto Territórios Digitais, Programa Um Computador por Aluno (PROUCA), Programa Inclusão Digital da Juventude Rural, Programa Redes Digitais de Cidadania, Programa Minas Inova e Centro de Qualificação em Tecnologia da Informação (CQTI) ou por constituírem políticas direcionadas à facilitação da aquisição de equipamentos e internet, como os programas Programa Inclusão Digital, Projeto Cidadão Conectado - Computador para Todos e Programa de Universalização do Acesso a Serviços de Telecomunicação em Minas Gerais. 
A terceira etapa da pesquisa, a entrevista semiestruturada, foi desenvolvida com o objetivo de entender a constituição dos espaços de acesso à internet disponíveis nas bibliotecas públicas municipais da Região Metropolitana de Belo Horizonte; verificar se as políticas públicas desenvolvidas pelos governos têm, de fato, atingido as bibliotecas que oferecem o serviço de acesso à internet e averiguar se há alguma prática de inclusão digital e social nas instituições.

A amostra da entrevista foi composta pelas bibliotecas que responderam ao questionário informando que possuem computadores para acesso à internet disponíveis à comunidade e que estão situadas em cidades adjacentes ao município de Belo Horizonte. Assim, integraram o grupo analisado as bibliotecas:

a) Biblioteca Pública Infantil e Juvenil de Belo Horizonte, Belo Horizonte;

b) Biblioteca Pública Municipal Anita Cabral de Barros, Ibirité;

c) Biblioteca Pública Municipal Dr. Edson Diniz, Contagem;

d) Biblioteca Pública Municipal Herbert Fernandes, Vespasiano;

e) Biblioteca Pública Municipal Ilka Maria Munhoz Gurgel, Ribeirão das Neves;

f) Biblioteca Pública Municipal Professor Francisco Tibúrcio de Oliveira, Santa Luzia;

g) Biblioteca Pública Municipal Professor Joaquim Sepúlveda, Sabará.

Foram analisados os seguintes tópicos:

a) Implantação do serviço de internet nas bibliotecas pesquisadas;

b) Existência de ações e impacto das políticas públicas de inclusão digital nas bibliotecas públicas municipais;

c) Perfil dos usuários do serviço de acesso à internet das bibliotecas pesquisadas;

d) Uso conjunto de informações disponíveis em fontes impressas e em formato digital nas bibliotecas pesquisadas;

e) Uso dos computadores para informações utilitárias e destinadas ao desenvolvimento cidadão nas bibliotecas pesquisadas;

f) Importância dos computadores com acesso à internet para as bibliotecas e para a comunidade atendida;

g) Orientação para uso da internet e desenvolvimento de competências em informação: habilidades para busca e uso de informações em meio digital.

Quanto aos resultados, as bibliotecas apresentaram dificuldades na identificação das trajetórias dos computadores na biblioteca, relacionadas à data de implantação do serviço, procedência dos equipamentos, amparo de políticas públicas, fato ocasionado principalmente pela ausência de registros da constituição dos equipamentos na instituição. Com relação às políticas públicas de inclusão digital desenvolvidas pelas prefeituras municipais, apresentaram desconhecimento de ações locais com este fim.

Machado (2010, p. 106) confirma tal apontamento: "A maioria dos municípios, tradicionalmente, se comporta como cliente das políticas idealizadas no nível central".A autora explica que a aplicação de políticas públicas municipais voltadas à cultura se dá, na maior parte dos casos, nos grandes municípios, que possuem uma estrutura de planejamento para a consolidação das propostas. Quando se trata daquelas voltadas à biblioteca pública é ainda mais difícil identificar ações, que normalmente são desenvolvidas pelos Sistemas Estaduais e/ou Municipais de Bibliotecas.

Com relação ao perfil do usuário que utiliza os computadores com acesso à internet são, na maioria, adolescentes e crianças. Contudo, outros grupos etários também utilizam os computadores com internet, mas em menor quantidade. As bibliotecas relataram que não há diferença no perfil de usuários que utilizam a internet e o acervo impresso, sendo o público adolescente, em idade escolar, o que mais frequenta as bibliotecas, seja para 
realização de trabalhos escolares em obras de referência impressas ou para o uso diverso da internet, na realização de pesquisas escolares e principalmente no uso de redes sociais e entretenimento.

Quanto à disponibilização de informações utilitárias nas bibliotecas, os gestores indicaram que a biblioteca não tem o hábito de oferecer informações nesse sentido, somente sob demanda. Nesse caso, auxiliam prontamente, seja por contato físico, ou oferecendo computadores, para serviços que demandam acesso à internet. A busca por esse tipo de serviço se dá em grande maioria por pessoas carentes, que solicitam um auxílio da biblioteca no sentido de os funcionários ouvirem as demandas e tentar direcionar a questão.

A respeito do uso da internet e desenvolvimento de competências em informação, as respostas indicaram que não são desenvolvidas práticas nesse sentido. Normalmente as demandas para auxílio no uso dos computadores são de usuários que não possuem nenhum conhecimento sobre informática, relacionadas ao processo de alfabetização digital, e são finalizadas no momento em que se supre aquela necessidade que foi levantada. A maioria dos usuários que tem familiaridade com recursos tecnológicos não demanda auxílio dos servidores e não existe um planejamento da biblioteca para oferecer treinamentos, também devido ao desinteresse expressado, pois normalmente o uso dos computadores se restringe ao acesso às redes sociais e entretenimento.

\section{CONSIDERAÇÕES FINAIS}

A Sociedade da Informação lança o desafio da inserção quase coerciva ao mundo tecnológico, sem considerar as dificuldades de colocação nessa nova realidade, seja pelo baixo poder aquisitivo, exclusão social, dificuldade de assimilação da nova tecnologia, desinteresse. Enquanto sujeitos com direitos e obrigações, o cidadão se vê compelido a adquirir habilidades para uso das tecnologias ou manter-se sob a dependência de pessoas que as possuam. Nesse contexto que evidencia necessidades informacionais e dificuldades de acesso, algumas bibliotecas públicas oferecem à comunidade computadores com acesso à internet e, em alguns casos, serviços de auxílio aos usuários, contribuindo para a inclusão digital por meio da alfabetização tecnológica e desenvolvimento de habilidades para busca e uso de informações.

Identificou-se que, das 27 bibliotecas públicas municipais da Região Metropolitana de Belo Horizonte pesquisadas, 11 oferecem o serviço de acesso à internet em suas dependências. Estes se constituíram a partir de cinco políticas públicas do Governo Federal, que equiparam o espaço com computadores, ofereceram monitores para auxílio aos usuários e conexão com a internet banda larga: Programa Mais Cultura, Programa Telecentros Comunitários, Programa Nacional de Apoio à Inclusão Digital nas Comunidades Telecentros.BR, Programa Nacional de Formação de Agentes de Inclusão Digital (Pnaid) e Programa Governo Eletrônico - Serviço de Atendimento ao Cidadão (GESAC).

Foram levantadas 28 políticas públicas de inclusão digital, representando um quantitativo considerável, contudo aspectos como a descontinuidade e a dispersão das ações em diversos órgãos governamentais dificultam a recuperação de informações sobre a aplicabilidade e validade das mesmas. Essas condições atingem os serviços de acesso à internet das bibliotecas públicas municipais, que se sustentam, muitas vezes, por meio dessas políticas públicas, posto que lidam diariamente com dificuldades de diversas ordens em sua realidade local. Nesse sentido, o desenvolvimento de políticas locais é um aspecto importante a ser ressaltado. A partir da investigação sobre as políticas de inclusão digital de âmbito municipal identificou-se que, dos sete municípios pesquisados, apenas Belo Horizonte desenvolve ações pontuais, as demais cidades são consumidoras de atos elaborados pela esfera federal e estadual, o que restringe as possibilidades de identificação de demandas locais e aplicações voltadas à realidade de cada instituição.

Dessa forma, quanto à avaliação dos serviços oferecidos pelas bibliotecas públicas pesquisadas, estes compreendem aspectos relacionados à inclusão digital técnica, conforme 
Lemos e Costa (2007), proporcionando o acesso à internet e algumas possibilidades de desenvolvimento de destreza no manuseio das máquinas. Não alcançam, no entanto, a dimensão cognitiva, de desenvolvimento de habilidades informacionais que compreende a autonomia e o posicionamento crítico para o uso independente das TIC, apesar da capacitação dos profissionais bibliotecários para o desenvolvimento de habilidades nessa dimensão.

\section{REFERÊNCIAS}

BENEVIDES, M. V. M. Cidadania e democracia. Lua Nova: Revista de Cultura e Política, São Paulo, n. 33, p. 5-16, Aug. 1994. Disponível em: <https://dx.doi.org/10.1590/S0102-64451994000200002>. Acesso em: 30 out. 2017.

BRASIL. Presidência da República. Decreto n. 3.294, de 15 de dezembro de 1999. Institui o Programa Sociedade da Informação e dá outras providências. Disponível em:

<http://www.planalto.gov.br/ccivil_03/decreto/d3294.htm>. Acesso em: 30 out. 2017.

BUNDY, A. For a clever country: information literacy diffusion in the 21st century. Kingston: Australian Library and Information Association, 2001. Disponível em:

<http://pandora.nla.gov.au/pan/38143/20040217-

0000/www.library.unisa.edu.au/about/papers/clever.htm>. Acesso em: 31 out. 2017.

CARVALHO, A. M. G.; AMÉRICO, M. T. Inclusão e cidadania digital no Brasil: a (des) articulação das políticas públicas. Redes.com: Revista de Estudios para el Desarrollo Social de La Comunicacion, Brasília, n. 9, p. 69-84, 2014. Disponível em: <http://hdl.handle.net/11449/135513>. Acesso em: 30 out. 2017.

CASTELLS, M. A galáxia da internet: reflexões sobre a internet, os negócios e a sociedade. Rio de Janeiro: Jorge Zahar Ed., 2003.

CUEVAS CERVERÓ, A.; VELLOSILLO GONZÁLEZ, I. As bibliotecas na prática da inclusão digital. In: CUEVAS CERVERÓ, A.; SIMEÃO, E. Alfabetização informacional e inclusão digital: modelo de infoinclusão social. Brasília: Thesaurus, 2011.

BELL, D. 0 advento da sociedade pós-industrial: uma tentativa de previsão social. São Paulo: Cultrix, 1973.

FERES, G. G.; BELLUZZO, R. C. B. Competência em informação: um diferencial da qualidade em publicações científicas. Revista Brasileira de Biblioteconomia e Documentação, São Paulo, v. 5, n. 1/2, p. 70-83,jan./dez. 2009. Disponível em: <https://rbbd.febab.org.br/rbbd/article/view/143>. Acesso em: 31 out. 2017.

FUNDAÇÃO BIBLIOTECA NACIONAL. Biblioteca pública: princípios e diretrizes. 2. ed. Rio de Janeiro: Fundação Biblioteca Nacional, 2000.

INSTITUTO PRÓ-LIVRO. Retratos da leitura no Brasil. 4. ed. São Paulo: IBOPE Inteligência, 2016. Disponível em: <http://prolivro.org.br/home/images/2016/Pesquisa_Retratos_da_Leitura_no_Brasil__2015.pdf>. Acesso em: 31 out. 2017.

INTERNATIONAL FEDERATION OF LIBRARY ASSOCIATIONS AND INSTITUTIONS - IFLA. Manifesto da IFLA/UNESCO sobre bibliotecas públicas. 1994. Disponível em:

$<$ https://www.ifla.org/files/assets/public-libraries/publications/PL-manifesto/pl-manifestoptbrasil.pdf>. Acesso em: 31 out. 2017.

INTERNATIONAL FEDERATION OF LIBRARY ASSOCIATIONS AND INSTITUTIONS - IFLA. Declaração de Alexandria sobre competência informacional e aprendizado ao longo da vida. Alexandria, 2005. Disponível em: <https://www.ifla.org/files/assets/wsis/Documents/beaconinfsoc-pt.pdf>. Acesso em: 31 out. 2017.

INTERNATIONAL FEDERATION OF LIBRARY ASSOCIATIONS AND INSTITUTIONS - IFLA. Diretrizes para o Manifesto IFLA/UNESCO sobre a Internet. 2006. Disponível em: <https://www.ifla.org/files/assets/faife/publications/policy-documents/internet-manifestoguidelines-pt.pdf>. Acesso em: 31 out. 2017. 
LEMOS, A.; COSTA, L. F. Um modelo de inclusão digital: o caso da cidade de Salvador. In: LEMOS, A. (Org.). Cidade digital: portais, inclusão e redes no Brasil. Salvador: EDUFBA, 2007. p. 35-47.

THE LIBRARY ASSOCIATION. Community informations: what libraries can do: a consultive document. London: Library Association, 1980.

MACHADO, E. C. Análise de políticas públicas para bibliotecas no Brasil. InCID: Revista de Ciência da Informação e Documentação, Ribeirão Preto, v. 1, n. 1, p. 94-111, 2010. Disponível em: <http://www.revistas.usp.br/incid/article/view/42307/45978>. Acesso em: 31 out. 2017.

MACHADO, E. C.; CALIL JÚNIOR, A.; ACHILLES, D. Mapeamento das políticas culturais nacionais voltadas para as bibliotecas públicas no Brasil. In: ENCONTRO NACIONAL DE PESQUISA EM CIÊNCIA DA INFORMAÇÃO, 15., 2014, Belo Horizonte. Anais... Belo Horizonte: UFMG, 2014. p. 2283-2301.

MARSHALL, T. H. Cidadania, classe social e status. Rio de Janeiro: Zahar, 1967.

MARTELETO, R. M. Redes sociais, mediação e apropriação de informações: situando campos, objetos e conceitos na pesquisa em Ciência da Informação. Tendências da Pesquisa Brasileira em Ciência da Informação, João Pessoa, v. 3, n. 1, p. 27-46, jan./dez. 2010.

MONTEIRO, S. A.; SILVA, J. L. C. Serviços de informação utilitária em bibliotecas universitárias. Revista ACB: Biblioteconomia em Santa Catarina, Florianópolis, v. 19, n. 1, p. 61-68, jan./jun. 2014. Disponível em: <https://revista.acbsc.org.br/racb/article/view/918>. Acesso em: 31 out. 2017.

SANTOS, P. L. V. A. C. As novas tecnologias na formação do profissional da informação. In: VALENTIM, M. L. (Org.). Formação do profissional da informação. São Paulo: Polis, 2002. p. 103-116.

SEBASTIÃO, S.; PACHECO, A.; SANTOS, M. Cidadania digital e participação política: o caso das petições online e do orçamento participativo. Estudos em Comunicação, n. 11, p. 31-51, maio 2012. Disponível em: <http://www.ec.ubi.pt/ec/11/pdf/EC11-2012Mai-02.pdf>. Acesso em: 31 out. 2017.

SILVA, J. F. M. O impacto tecnológico no exercício profissional em Ciência da Informação: o bibliotecário. In: VALENTIM, M. L. P. (Org.). Atuação profissional na área de informação. São Paulo: Polis, 2004. p. 83-96.

SILVEIRA, S. A. A noção de exclusão digital diante das exigências de uma cibercidadania. In: HETKOWSKI, T. M. Políticas públicas \& inclusão digital. Salvador: EDUFBA, 2008. p. 43-66.

SORJ, B. Brasil@povo.com: a luta contra a desigualdade na Sociedade da Informação. Rio de Janeiro: Jorge Zahar Ed., 2003.

SUAIDEN, E. Biblioteca pública e informação à comunidade. São Paulo: Global, 1995.

Editores do artigo: Enrique Muriel-Torrado e Adilson Luiz Pinto 